Academic Platform Journal of Engineering and Science

\title{
İş Sağlığı Ve Güvenliği Yönetim Sistemlerinde Risklerin Yapay Sinir Ağlarıyla Değerlendirilmesi
}

\author{
${ }^{1}$ Ercüment Neşet DİZDAR, *2 Oğuz KOÇAR \\ ${ }^{1}$ Çankırı Karatekin Üniversitesi, Yapraklı MYO, İş Sağlığı ve Güvenliği Programı, Çankırı, endizdar@yahoo.com.tr, \\ ${ }^{2}$ Bülent Ecevit Üniversitesi, Mühendislik Fak., Mekatronik Mühendisliği Bölümü, Zonguldak, oguz.kocar@yahoo.com.tr, \\ Araştırma Makalesi \\ Geliș Tarihi: 23.05.2018 \\ Kabul Tarihi: 27.07.2018
}

Öz

İş Sağlığ1 ve Güvenliğinde karşılaşılabilecek tüm tehlike ve risklerin sistematik ve verimli biçimde yönetilmesi, sürecin sürekli iyileştirme yaklaşımı çerçevesinde çözümlenmesi İş Sağlığı ve Güvenliği Yönetim Sistemleri (İSG-YS) vasıtasıyla olur. Endüstriyel kuruluşlarda muhtemel kazaların insanlara ve çevreye olan zararlarının en aza indirilmesi amacıyla, yüksek seviyede, etkili ve sürekli korumanın sağlanması gerekmektedir. Bu bağlamda, kurumların Risk Değerlendirme Metotlarını kullanarak, mümkün olan en yüksek seviyede ki doğrulukla karar vermesi beklenmektedir. İSG-YS'nde, risk değerlendirme metotlarından olan nicel yöntemle tehlikeler için üretilen senaryolarda kazaların muhtemel sonucunun meydana gelme sıklıkları düşürülmeye çalışılmaktadır. Bu çalışmada, Yapay Sinir Ağları (YSA) yaklaşımı, Nicel (Kantitatif) Risk Değerlendirmesi olarak İSG-YS'ne destek olacak şekilde tasarlanmıştır. İSG tehlikelerinin bulunduğu kurumlardaki kazaların vuku bulma olasılıkları YSA ile ele alınarak yorumlanması için farklı modeller geliştirilmiştir. Geliştirilen modellerin performansları belirleme katsayısı $\left(\mathrm{R}^{2}\right)$ ve Karesel Hataların Karekökü (Root Mean Square Error) ölçütleri içinde değerlendirilmiştir. Yapay Sinir Ağları ile geliştirilen model ile, giriş ve istenilen çıkış değerlerinin tekrar tekrar ağa uygulanmasıyla eğitimi gerçekleştirilerek, hataların minimize edilmesiyle olası kazaların sıklığını öngören öğrenmeler gerçekleştirilmiştir. Bu şekilde, yeni girişlerin kazandığı deneyime göre olası iş kazalarının aylara göre frekansları tahmin edilerek, üst yönetime güvenilir karar desteği sağlanmıştır.

Anahtar kelimeler: İSG Yönetim Sistemleri, Nicel Risk Değerlendirme, Yapay Sinir Ağları, İş Sağlığı ve Güvenliği

\section{Evaluation of Risks of OSH Management System with Artificial Neural Networks}

\author{
${ }^{1}$ Ercüment Neşet DİZDAR, *2O ğuz KOÇAR \\ ${ }^{1}$ Çankırı Karatekin University, Yapraklı Technical and Business Collage, Occupational Health and Safety Programme, Çankırı, \\ endizdar@yahoo.com.tr \\ ${ }^{* 2}$ Bülent Ecevit University, Faculty of Engineering, Mechatronics Eng. Department. Zonguldak, oguz.kocar@yahoo.com.tr
}

\begin{abstract}
All hazards and risks that may be encountered in Occupational Safety and Health are systematically and efficiently managed, and the process is solved through Occupational Safety and Health Management Systems (OSHMS) within the framework of the continuous improvement approach.

Effective and continuous protection must be provided at a high level in industrial establishments in order to minimize the loss of possible accidents to people and the environment. In this context, institutions are expected to use the "Quantitative Risk Assessment Methodologies" to make decisions with the highest possible accuracy. In the OSH Management Systems, quantitative risk assessments are attempted to reduce the frequencies of possible consequences of the accidents that are scenarios for the hazards. The Artificial Neural Networks (ANN) approach is designed to support the OSH Management System as a Quantitative Risk Assessment.

In the study, different models were developed for interpreting the probabilities of occupational accidents in institutions where severe OSH hazards are present, by taking into account the ANN. The coefficients of the performance determinants $\left(\mathrm{R}^{2}\right)$ and the Root Mean Square Error of the developed models were evaluated. Models developed with Artificial Neural Networks, training of input and wanted output values by repeatedly applying to the network, learning realized by predicting possible
\end{abstract}


accidents by minimizing faults. In this way, the frequencies of the probable occupational accidents according to the months of the new entries are estimated according to the experiment, and the top management provides reliable decision support.

Keywords: OSH Management Systems, Quantitative Risk Assessment, Artificial Neural Networks, Occupational Safety and Health

\section{GÍRIŞ}

Günümüzde, kuruluşlardan beklentiler artmıştır. Artık sadece iyi mal veya hizmeti ucuza sunmak ve ISO9001 Kalite Yönetim Sistemi ile sunulan bu ürünü güvence altına almanın yanında kuruluşların ürün veya hizmeti üretirken çevreye saygılı olmaları, İş Sağlığı ve Güvenliği ile ilgili önlemleri almaları ve sosyal sorumluluklarını yerine getirmeleri beklenmektedir. İster üretim isterse hizmet sektöründe olun çalışma ortamının çalışanlar için sağlıklı ve güvenli hale getirilmesi zorunlu hale gelmiştir. Çalışma ortamlarındaki olası risklerin tespit edildiği, bu riskleri yok etmek için ilgili mevzuata ve standartlara uygun programların oluşturulduğu ve uygulandığı yönetim yap1 ve felsefesine "İ̧̧ Sağlığı ve Güvenliği Yönetim Sistemi” adı verilmektedir [1-8].

İş Sağlığg ve Güvenliği Yönetimi, içinde bulunulan şartların ergonomik hale getirilmesi (bir bakıma iyileştirilmesi), tehlike ve risklerin tanımlanmasından analizine, gerekli tedbirlerin alınmasından, uygulamadaki aksaklıkların tespiti ve müdahalesine kadar İSG amaçları doğrultusunda, süreç boyunca organizasyon, iletişim ve danışmanlığın temin edilmesini ihtiva eder. ISG-YS, kuruluşların faaliyetlerinin genel stratejileri ile uyumlu olarak sistematik bir şekilde ele alınıp sürekli iyileştirme yaklaşımı çerçevesinde çözümlenmesini amaçlar [6,9 - 11].

İSG-YS'nde, çalışma hayatını, üretkenliği ve bunlara bağlı olarak işletmelerin kârlılıklarını etkileyen iş kazaları ve sağlık problemlerine önlem almak için, öncelikle mevcut durumun analizi yapılarak risklerin tespit edildiği, bu riskleri yok etmek için yasal yönetmelik, mevzuat ve kanunlara entegre programların oluşturulduğu ve uygulandığı, bütün çalışmaların belli bir sistematik içerisinde dokümante edilerek ve ilgilenenlere duyurulduğu, bu yürütülmekte olan çalışmaların izlenip denetlenmektedir [2, 12-16].

İSG Yönetim Sistemiyle, çalışanlar, yönetenler ve denetleyenlerin rol ve sorumlulukları açık hale getirilerek çalışanların katılımını sağlayacaktır. İSG-YS'nde risklerin, önceliklerin tespit edilmesin de geçmiş yıllarda ki verilerin analizi ve bu analize dayalı değerlendirmeler önemlidir. Bu değerlendirmeler ISG-YS'nin karar mekanizmaları yönlendirici rol oynar [17-20].

İşletmelerde risklerin sadece olasılık ve şiddetinin hesaplanması o işletmedeki kaza olasılığını ve riskini ortadan kaldırmaz. Önemli olan belirlenen risklere uygun kontrol önlemlerinin alınabilmesidir. Riskin değerlendirilmesinde "Karşı karşıya kalınan riskler kabul edilebilir midir?” ve "Kabul edilemeyecek riskler için hangi önlemler alınmalıdır?" sorularına cevap bulunmalıdır. İşyerlerinde doğru uygulanan risk değerlendirme çalışmaları sonucunda olası tehlikelerle ilgili alınacak önlem ve bu minvalde oluşturulacak bütçeler çok ciddi hesaplanmalı ve harcama kalemleri planlanmalıdır. Ancak bu şekilde, yani yerinde ve zamanında alınacak önlemlerin doğru tespitiyle yönetilen İSG çalışmaları, işyeri koşullarında iyileşme getirmekte ve dolayısıyla iş kazası ile meslek hastalığı sıklık hızı ile ağırlık hızında düşme sağlamalıdır [13, 21 - 23].

Bu çalışma kapsamında, yedi yıllık dönemde metal işleme sektöründe aday çalışanları kapsayan 235 kaza tutanağı derlenmiştir. YSA ile oluşturulan modelin giriş parametreleri olarak kazanın gerçekleştirildiği ay ve yıl esas alınarak kaza sonucu meydana gelebilecek kayıp iş gücü tahmin edilmeye çalışılmıştır. Modelin uygulanabilirliğini görebilmek için, modelin sonuçları gerçek değerlerle karşılaştırılmıştır. Geliştirilen model ile, üst yönetimin risk değerlendirme çalışmalarında ciddi bir destek sağlanması amaçlanmıştır.

\section{RISK DEĞERLENDİRME}

\subsection{ISG-YS'de Risk Değerlendirme}

Her işyerinde çalışma şartlarından ve yapılan işten kaynaklanan çeşitli riskler bulunmaktadır. Olası risklerin sebep olabileceği kazalar maddi hasarların yanında çalışanların yaralanmalarına, hastalanmalarına geçici veya sürekli iş gücü kayıplarına neden olabilir. Muhtemel kazaların insanlara ve çevreye olan zararlarının en aza indirilmesi amacıyla, yüksek seviyede, etkili ve sürekli korumanın sağlanması gerekmektedir [3, 24, 25].

ISG-YS'yle risk değerlendirmesi, herhangi bir sistemde tehlikelerden kaynaklanan risklerin büyüklügüunü tahmin etme ve mevcut kontrollerin yeterliliğini dikkate alarak bu risklerin kabul edilebilir olup olmadığına karar verme sürecidir. Günümüzde birçok risk değerlendirme tekniği mevcuttur. Risk değerlendirme teknikleri, risklerin, risklerin gerçekleşme olasılıklarının ve olası etkilerinin tahmin edilmesi açısından iki ana grupta toplanabilir. Bunlar, kalitatif ve nicel yöntemlerdir [18, 20, 25, 26].

Kalitatif yöntemlerde, matematiksel risk değerlendirmesi yerine sözel mantıkla risk değerlendirmesi yapılmakta, uygulamayı yapan uzman kendi tecrübelerine ve sezgilerine dayanarak riskleri ve risk öncelik değerlerini tahmin etmektedir. Tahminî risk hesaplanırken ve ifade edilirken rakamsal değerler yerine yüksek, çok yüksek gibi tanımlayıcı değerler kullanılır [27 - 29]. Bu tahmin tamamen subjektif değerlendirmelere dayanmakta ve çoğu zaman da sistematik bir nitelik göstermemektedir. Bu tür 
yöntemlerde, değerlendirmeyi yapan uzmanın sezgi ve muhakeme kabiliyeti, yöntemin güvenirliliği açısından önemlidir. $\mathrm{Bu}$ nedenle, kritik öneme haiz sistemlerde sadece kalitatif yöntemlerle risk değerlendirmesi yapmak doğru değildir [27, 30 - 33].

Nicel risk değerlendirme yöntemleri, riski hesaplarken sayısal yöntemlere başvurur. Bu sayısal yöntemler, olasılık ve güvenirlik teoremleri gibi basit teknikler olabileceği gibi, simülasyon modelleri gibi karmaşık tekniklerde olabilir. Nicel risk analizinde tehlikeli bir olayın meydana gelme ihtimali, tehlikenin etkisi gibi değerlere sayısal değerler verilir ve bu değerler matematiksel ve mantıksal metotlar ile işlenip risk değeri bulunur [34 - 36].

Nicel risk analizini kullanan bazı endüstriler ve kullandıkları metotlar Tablo 1'de verilmiştir.

Tablo 1. Bazı nicel risk değerlendirme metotları

\begin{tabular}{|c|c|c|c|}
\hline Metot & Kaynak & Özellik & Endüstri \\
\hline OCAVE & $\begin{array}{c}\text { Carnegie Mellon } \\
\text { Üniver.Yazılım } \\
\text { Enstitüsü }\end{array}$ & Nicel & Yazılım \\
\hline $\begin{array}{c}\text { Yerleşik } \\
\text { Risk Analizi } \\
\text { Prosesi } \\
\end{array}$ & Tom Peltier, 2005 & Nicel & Genel \\
\hline $\begin{array}{l}\text { CCTA Risk } \\
\text { Analysis } \\
\text { and } \\
\text { Manegemen } \\
\text { t Method } \\
\end{array}$ & $\begin{array}{c}\text { Merkezi } \\
\text { Bilgisayar ve } \\
\text { Telekomünikasyon } \\
\text { Ajans1 }\end{array}$ & Nicel & NATO \\
\hline $\begin{array}{c}\text { Olay Ağacı } \\
\text { Analizi }\end{array}$ & $\begin{array}{c}\text { (ISC)2 bilgi } \\
\text { sistemleri güvenlik } \\
\text { mühendisliği } \\
\text { profesyonel }\end{array}$ & Nicel & $\begin{array}{l}\text { Yazilım } \\
\text { ve } \\
\text { donanım }\end{array}$ \\
\hline $\begin{array}{l}\text { Olası Hata } \\
\text { Türleri ve } \\
\text { Etki Analizi } \\
\text { Metodolo. }\end{array}$ & US Ordusu, 1940 & Nicel & $\begin{array}{l}\text { Otomobil } \\
\text { havacılık }\end{array}$ \\
\hline
\end{tabular}

İSG-YS'nde, nicel risk değerlendirmeleri ile tehlikeler için senaryo edilen her bir kazanın olası sonucunun meydana gelme frekanslarının düşük seviyelere indirilmesi zorunludur. $\mathrm{Bu}$ yüzden, kurumlar, güvenilirlik verisi ile kaza senaryolarında kullanılacak olasılık değerlerini, nicel yaklaşımlarla eksiksiz ve en doğru şekilde hesaplamış olması gerekir

\subsection{Risk Değerlendirme Süreci}

İSG-YS'nde risk değerlendirme süreci, planlama, çalışmaların sınıflandırılması, bilgi toplama, tehlikelerin tanımlanması, risklerin değerlendirilmesi gibi aşamalardan oluşmaktadır [37- 39].

Risklerin değerlendirmesi çalışmaları, mevcut mevzuat ve işyeri koşulları çerçevesinde planlama aşamasında gerçekleştirilir. İşyerinde yürütülen çalışmalarının sınıflandırılmasında ise, yürütülmekte olan veya yürütülecek faaliyetler özelliklerine göre sınıflandırmaya tabi tutulur. Sinıflandırmada, sürekli olmamakla birlikte periyodik olarak veya değişen aralıklarla yürütülen bakım ve onarım gibi faaliyetler de dikkate alınır. Sınıflandırmada, işyerinin içinde ve dışında yürütülen işler, üretim veya hizmet sürecinin aşamaları, planlanmış veya ani faaliyetler, çalışanların görev tanımları gibi unsurlardan da yararlanılabilmektedir.

Bilgi ve veri toplamada, işyerinde yürütülen işler, bu işlerin süresi ve sıklığ 1 , işin yürütüldüğü yer, işin kim veya kimler tarafından yürütüldüğü, yürütülen işten etkilenebilecek olanlar, alınmış olan eğitimler, işin yürütümü için ön izin gerekip gerekmediği, işin yürütümü sırasında kullanılacak makine ve ekipman, bu makine ve ekipmanların kullanım talimatları, kaldırılacak veya taşınacak malzemelerle bunların özellikleri, kullanılan kimyasallar ve özellikleri, mevcut korunma önlemleri, daha önce meydana gelmiş olan iş kazası veya meslek hastalıkları gibi unsurlar dikkate alınır. Tehlikelerin tanımlanmasında ise tehlike veya kaynaklarının bulunup bulunmadığı, tehlike varsa bundan kimlerin ve ne şekilde etkilenebileceği dikkate alınarak yapılır. Risklerin değerlendirilmesinde, riskin niteliksel olarak analizi için Kalitatif Risk Değerlendirme Tablosu'ndan da faydalanılır.

$\mathrm{Bu}$ tablo, risklerin değerlendirilmesinde, değerlendirme sonuçlarına göre hangi işlere öncelik verilmesi ve kaynakların öncelikle nereye aktarılması konularında kullanılan bir tekniktir. Bu tablonun hazırlanması, sistemin risklerinin tahmini için geçmişteki olaylardan kazanılan deneyimlere başvurma anlayışına dayanmaktadır [7, 19, 30, $35,40,41,42]$. Şekil 1'de örnek bir risk değerlendirme matrisi yer almaktadir.

\section{Risk Matrisi}

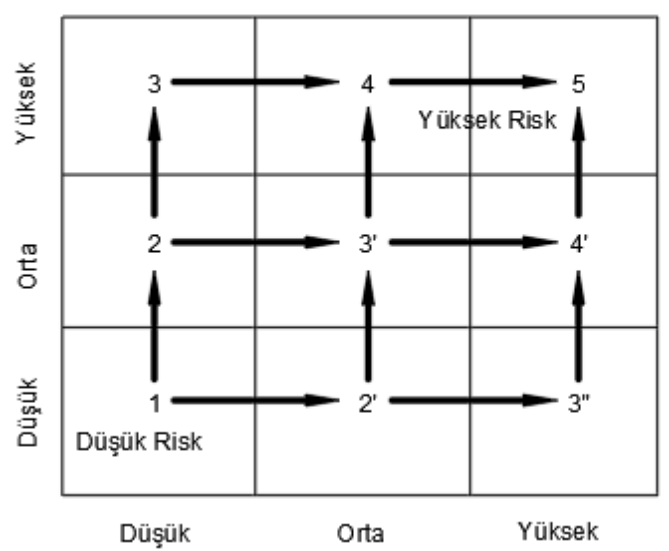

Şekil 1. Kalitatif risk değerlendirmede frekans ve sonuçları ile olas1 riskin dururumu

$\mathrm{Bu}$ bağlamda, kurumların sayısal tabanlı (kantitatif) risk değerlendirme metodolojilerini devreye sokarak, mümkün olan en yüksek önlem seviyesinde karar vermesi beklenmektedir. 


\subsection{Yapay Sinir Ağları}

Literatür incelediğinde farklı metotları içiren tahmin çalışmaları bulunmaktadır. $\mathrm{Bu}$ çalışmalardan bazıları kazaya sebep veren faktörlerin incelenmesine imkan veren regresyon analizi ve YSA [25], çoğunlukla trafik kazaların ele alınmasinda kullanilan YSA [43 -49], tersane kazalarının tahmininde genetik algoritma [50], tersanelerde meydana gelen iş kazalarında çalışma şartlarının etkisini incelemek ve çalışma yerindeki kaza risklerinin tahmininde ANFİS [51] kullanıldığı belirlenmiştir. Bu çalışmada İSGYS'nde risklerin belirlenmesinde kullanılan yöntemlere alternatif olarak YSA kullanılmıştır. Yapay Sinir Ağları (YSA), insandan esinlenerek öğrenme sürecinin matematiksel modellenmesi sonucunda ortaya çıkan bir veri işleme sistemidir. İnsan beyninin özelliklerinden olan öğrenme, hatırlama, yeni bilgiler oluşturabilme, genelleme yapabilme ve keşfedebilme gibi yetenekleri taklit etmeye çalışan, basit işlemcilerden oluşmuş bir yapıdır [52, 53, 54]. YSA'yı oluşturan temel işlemci yapay nörondur (Şekil 2).

Bir yapay nöronda girişler $\mathrm{x}_{\mathrm{i}}$, ağırlıklar $\mathrm{w}_{\mathrm{i}}$ toplama fonksiyonu $(\Sigma)$, aktivasyon fonksiyonu (f) ve çıkış (y) bulunmaktadir.

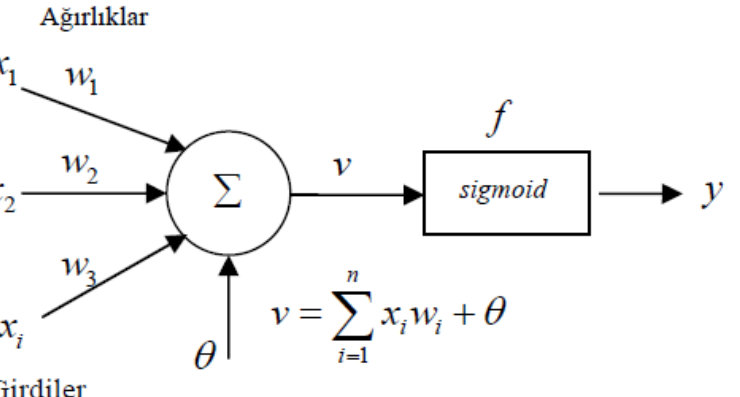

Girdiler

Şekil 2. Temel Yapay Sinir Ağı Hücresi: Yapay Nöron

Şekil 2'de görülen temel YSA hücresi inceleyecek olursa, $\mathrm{x} 1, \mathrm{x} 2, \ldots . ., \mathrm{xi}$ değerleri hücre girdileridir. Alınan girdiler belli ağırlıklarla çarpılır ve -1 ila +1 arasında değişen eşik değeri ile toplanarak net girdi oluşturulur. Aktivasyon fonksiyonunda net girdi üzerinde işlem yapılarak hücre çıktısı istenilen aralıklara getirilmeye çalışılır. Bu çıkış değeri, sistem için bilinen çıkış ile karşılaştırılarak bir hata oranı bulunur. Bu hata oranına göre yapay sinir ağı hücresi, girdilerin yeni ağırlık oranlarını günceller. Böylece daha doğru sonuçlar alabilmemiz için bir döngü sağlanmaktadır. Ağın öğrenme olayı da bu ağırlıkların güncellenmesi ile meydana gelir.

$y=\sum_{i=1}^{n}\left(w_{i} x_{i}+\theta\right)$

Aktivasyon fonksiyonu hücreye gelen net girdiyi işleyerek hücrenin bu girdiye karşılık üreteceği çıktıyı belirler. Aktivasyon fonksiyonu genellikle doğrusal olmayan bir fonksiyon seçilir. Yapay sinir ağlarının bir özelliği olan "doğrusal olmama" aktivasyon fonksiyonlarının doğrusal olmama özelliğinden gelmektedir. Aktivasyon fonksiyonu seçilirken dikkat edilmesi gereken bir diğer nokta ise fonksiyonun türevinin kolay hesaplanabilir olmasıdır. Geri beslemeli ağlarda aktivasyon fonksiyonunun türevi de kullanıldığı için hesaplamanın yavaşlamaması için türevi kolay hesaplanır bir fonksiyon seçilir. Şekil 3'de YSA'da kullanılan aktivasyon fonksiyonları listelenmiştir.

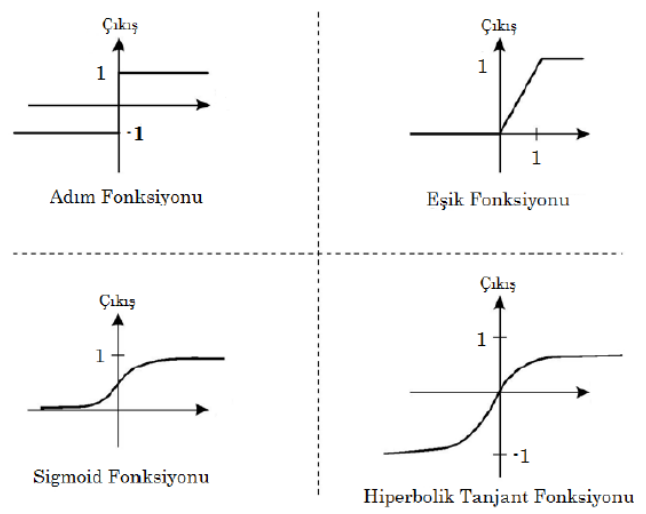

Şekil 3. Yapay sinir ağlarında en çok kullanılan aktivasyon fonksiyonları

Hücrenin çıktısı, aktivasyon fonksiyonu tarafından belirlenen çıktı değeridir. Üretilen çıktı dış dünyaya veya başka bir hücreye gönderilir. Hücre kendi çıktısını kendisine girdi olarak da gönderebilir. Bir proses elemanının birden fazla çıktısı olmasına rağmen sadece bir çıktısı olabilir [55].

Tablo 2. İş kazaları verilerinin yıllara göre dağılımı

\begin{tabular}{cc}
\hline Yıllar & İș Kazası Sayısı \\
\hline 1 & 12 \\
2 & 49 \\
3 & 26 \\
4 & 21 \\
5 & 37 \\
6 & 64 \\
7 & 26 \\
Toplam & 235 \\
\hline
\end{tabular}

YSA'nın; doğrusal olmayan yapıları modelleyebilmesi, paralel dağılmış yapısı, öğrenme ve genelleme yapma yeteneği, farklı problemler için uyarlanabilirliği, hata toleransına sahip olması en önemli özelliklerindendir. YSA'nın bu özellikleri işletme, finans, mühendislik, tıp vb. birçok farklı alanda tercih edilmelerini sağlamıştır. YSA'nın birçok türü vardır. YSA'lar tiplerine, katman sayılarına, yapılarına ve öğrenme algoritmalarına göre sınıflandırılabilirler (Şekil 4).

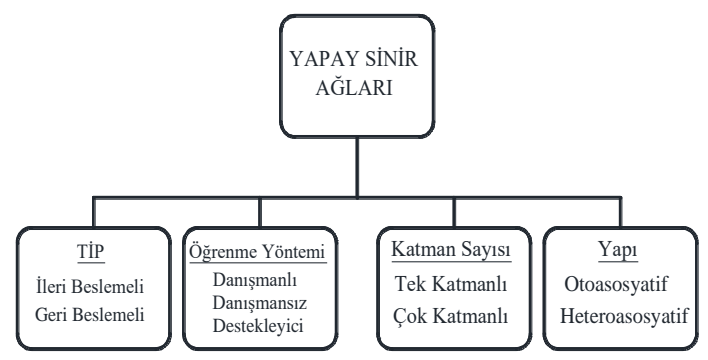

Şekil 4. YSA'nın sınıflandırılması [56]. 


\section{MALZEME VE YÖNTEM}

\subsection{Verilerin Toplanması}

Metal sektöründe sektöründe faaliyet gösteren fabrikadan elde edilen 235 kaza tutanağı elde edilmiştir. Tutanaklar 7 yıllık bir döneme ait olup, "aday çalışan" olarak tanımlanan işçilere aittir (Tablo 2). Kaza tutanakları ayrıntılı bir şekilde incelenerek ay, yıl ve kaza sonrası işe dönüş süreleri dikkate alınmıştır.

Tablo 3. Kaza tutanaklarından toplanan bilgiler

\begin{tabular}{|c|c|c|c|c|c|c|}
\hline Kaza No & Doğum Tarihi & İşe Giriş Tarihi & Kaza Tarihi & İş Başı Tarihi & Kaza Türü & $\begin{array}{c}\text { Kayıp İş } \\
\text { Günü }\end{array}$ \\
\hline 3128 & 17.10.1977 & 17.03 .1 & 10.06 .1 & 14.06 .1 & $\begin{array}{c}\text { Sicak Malzemeyle } \\
\text { Yanma }\end{array}$ & 4 \\
\hline 3131 & 9.09 .1980 & 9.03 .1 & 19.06.1 & 21.06 .1 & Cisim Sıçraması & 2 \\
\hline 3133 & 11.08.1977 & 21.05 .1 & 26.06 .1 & 30.06 .1 & $\begin{array}{c}\text { Sicak Malzemeyle } \\
\text { Yanma }\end{array}$ & 4 \\
\hline 3143 & 1.01 .1976 & 2.01.1 & 5.07 .1 & 7.07.1 & Cisim Arasına Sıkışma & 2 \\
\hline 3138 & 2.07.1978 & 8.04 .1 & 26.07 .1 & 15.08 .1 & Yüksekten Düşme & 20 \\
\hline 3136 & 19.05.1975 & 23.02 .1 & 29.07 .1 & 12.08 .1 & Düzde Düşme & 14 \\
\hline 3152 & 7.03 .1972 & 27.05 .1 & 9.08 .1 & 18.08 .1 & Cisim Sıçraması & 9 \\
\hline 3145 & 14.08.1972 & 22.02 .1 & 27.08 .1 & 9.09 .1 & Cisim Arasına Sıkışma & 13 \\
\hline 3178 & 3.05 .1979 & 10.03 .1 & 8.10 .1 & 8.11 .1 & Cisim Düşmesi & 31 \\
\hline 3182 & 11.09 .1975 & 23.02 .1 & 23.10 .1 & 3.11 .1 & Yüksekten Düşme & 11 \\
\hline 3183 & 1.07 .1977 & 2.01 .1 & 25.10 .1 & 27.12 .1 & Cisim Arasına Sıkışma & 63 \\
\hline 3165 & 1.01 .1971 & 2.01 .1 & 24.11 .1 & 26.11 .1 & Trafik & 2 \\
\hline 2987 & 1.02 .1969 & 1.02 .1 & 2.01 .2 & 12.01.2 & Elektrik Çarpması & 10 \\
\hline 2988 & 1.02 .1970 & 28.08 .1 & 2.01 .2 & 29.02 .2 & Cisim Arasına Sıkışma & 58 \\
\hline 2993 & 5.08 .1980 & 15.10 .1 & 30.01 .2 & 14.02 .2 & Düzde Düşme & 15 \\
\hline 2980 & 4.06 .1973 & 11.09 .1 & 4.02 .2 & 14.02 .2 & Cisim Arasına Sıkışma & 10 \\
\hline 2984 & 1.01 .1970 & 1.02 .1 & 17.02 .2 & 17.02 .2 & Maden Yanması & 10 \\
\hline 2977 & 1.01 .1978 & 2.02 .1 & 28.03 .2 & 26.04 .2 & Cisim Çarpması & 29 \\
\hline 2969 & 30.11 .1974 & 6.06 .1 & 19.04.2 & 28.04 .2 & $\begin{array}{c}\text { Sicak Malzemeyle } \\
\text { Yanma }\end{array}$ & 9 \\
\hline 2971 & 23.05.1971 & 17.12 .1 & 27.04 .2 & 4.05 .2 & Cisim Çarpması & 7 \\
\hline 2958 & 26.09.1978 & 21.09 .1 & 7.05 .2 & 16.05 .2 & Yüksekten Düşme & 9 \\
\hline 2960 & 15.11.1976 & 4.02 .1 & 13.05 .2 & 17.05 .2 & Cisim Düşmesi & 4 \\
\hline 2950 & 30.04 .1978 & 1.10 .1 & 9.06 .2 & 12.06 .2 & Yüksekten Düşme & 3 \\
\hline 2929 & 1.01 .1976 & 1.01 .2 & 10.06 .2 & 25.07 .2 & Cisim Arasına Sıkışma & 45 \\
\hline 2930 & 1.01 .1980 & 1.01 .1 & 12.06 .2 & 12.08 .2 & Cisim Arasına Sıkışma & 61 \\
\hline 2946 & 8.02 .1973 & 1.04 .1 & 14.06 .2 & 14.06 .2 & Düzde Düşme & 0 \\
\hline 2949 & 15.02.1977 & 20.04 .2 & 15.06 .2 & 24.06 .2 & Cisim Arasına Sıkışma & 9 \\
\hline 2952 & 30.07 .1976 & 12.03 .1 & 28.06 .2 & 30.06 .2 & Cisim Çarpması & 2 \\
\hline 2956 & 1.01 .1972 & 20.06 .2 & 30.06 .2 & 4.07 .2 & Makinalara Kaptırma & 4 \\
\hline
\end{tabular}

\subsection{Verilerin İncelenmesi}

Kaza raporundan elde edilen bilgiler; kaza zamanına ait faktörler (y1l, ay, vardiya, vardiya saati vb), kazaliya ait faktörler (tecrübe, yaş, unvan vb), kaza yerine ait faktörler (tesis, atölye vb), kaza sebebine ait faktörler (oluş şekli, yaralanan organ vb) olarak siralanabilir. Belirtilen faktörlerin analizi için çeşitlerine göre seviyelendirilip, özel bir kodlama sistemiyle sayısal dönüşümler gerçekleştirilmektedir.
Kaza zamanına ait faktörler:
- Yll

gösterir,

- Ay

Kazalıya ait faktörler:

- İş kaybı

açıklar.

Cevap Değişkeni olarak:
Kazanın hangi yılda olduğunu Kazanın gerçekleştiği ay

Kazalının işe dönüş süresini 
- Cevap Değişkeni Belirtilen ay ve yılda kazanın meydana gelme olasılığını belirtir.

Kaza tutanakları ilk önce yıllara göre, sonra kendi içinde aylara göre ayrılmıştır. Her ayda meydana gelen ve her kazada meydana gelen iş günü kayıpları belirlenmiştir.

Tablo 3'de 7 yıllık dönemde aday işçilerle ilgili toplanan bazı bilgiler bulunmaktadır.

Kaza tutanaklarındaki ham veriler kazanın gerçekleştiği ay, y1l ve kayıp iş gününe göre düzenlenmiştir. Tablo 4'de 3 yıla ait düzenlenmiş veriler görülmektedir.

Tablo 4. 3. Y1la ait veriler

\begin{tabular}{|c|c|c|}
\hline Ay & Y1l & Kayıp İş Günü \\
\hline 1 & \multirow{25}{*}{3} & 10 \\
\hline & & $\begin{array}{l}10 \\
7\end{array}$ \\
\hline & & 10 \\
\hline 2 & & 10 \\
\hline & & 9 \\
\hline & & 1 \\
\hline 3 & & 67 \\
\hline & & 4 \\
\hline & & 3 \\
\hline 4 & & 2 \\
\hline & & 0 \\
\hline 5 & & 0 \\
\hline & & 10 \\
\hline 6 & & 0 \\
\hline 7 & & 10 \\
\hline & & 9 \\
\hline 8 & & 0 \\
\hline & & 12 \\
\hline 9 & & 8 \\
\hline & & 0 \\
\hline 10 & & 3 \\
\hline & & 20 \\
\hline & & 3 \\
\hline 11 & & 6 \\
\hline 12 & & 0 \\
\hline
\end{tabular}

Son olarak veri setinin oluşturulması için aynı yıl ve aynı ay içinde meydana gelen kazalarda ki kayıp iş günlerinin toplamı alınmıştır. Tablo 5'de elde edilen altmış altı setten oluşan veri seti görülmektedir.

\subsection{YSA Mimarisi}

Çalışmada, her biri kendi belleğine sahip işlem elemanlarından oluşan paralel ve dağıtılmış bilgi işleme yapılarından oluşan, bir bakıma biyolojik sinir ağlarından ilham alan YSA yaklaşımı, nicelbir risk değerlendirmesi olarak İSG-YS'ne destek olacak şekilde tasarlanmıştır.

Yapılan çalışmada, ciddi İSG tehlikelerinin bulunduğu kurumlardaki kazaların vuku bulma olasılıkları YSA'1 içerisinde yer alan ele alınarak yorumlanması için farklı modeller geliştirilmiştir.

Çalışmada kullanılan YSA mimarisi gizli katman, bir giriş katmanı ve bir çıkış katmanından oluşmaktadır (Şekil 1). Problemin yapısına göre giriş ve çıkış katmanlarındaki nöron sayısı, gizli katman sayısı ve gizli katmanlar da bulunan nöron sayısı belirlenmelidir. Bundan dolayı giriş katmanında işlem değişkenlerini temsil eden iki nöron bulunmaktadır. Çıkış katmanında ise kayıp iş gününü gösteren bir nöron bulunmaktadır. Bununla beraber gizli katman sayısı ve gizli katmandaki nöron sayısını belirlemek için bir kural bulunmamaktadır [57]. Bundan dolayı gizli katman ve gizli katmandaki nöron sayısını belirleyebilmek için farklı modeller oluşturulmuş ve modellerin eğitim ve test sonuçlarının Ortalama Mutlak Hata ve Ortalama Karesel Hataların Karekökü hesaplanmış ve karşılaştırılmıştır. En iyi sonucun elde edildiği model seçilmiştir.

635 adet iş kazası tutanağı incelenerek oluşturulan veri seti, giriş ve çıkış parametrelerine göre YSA'nda kullanılmak üzere düzenlenmiştir. Veri setlerinden 53 adeti eğitim amaçlı, 13 adeti ise test amaçlı olarak kullanılmıştır.

\subsection{YSA İçin Diğer Parametrelerin Belirlenmesi}

Kazanın oluş şeklinin tahmin edilmesinde kullanılmak üzere farklı özelliklere sahip 10 adet YSA modeli oluşturulmuştur. $\mathrm{Bu}$ modellerde üç farklı öğrenme algoritması kullanılırken, gizli katman sayısı, gizli katmanlarda ki nöron sayısı ve aktivasyon fonksiyonları değiştirilmiştir. Oluşturulan modeller Tablo 6'da verilmiştir.

YSA ile modelleme iki aşamadan oluşmaktadır. Birinci aşama "Eğitim Süreci", diğer aşama ise "Test Süreci"dir. Eğitim sürecinde ağa verilen giriş ve çıkış değerleri kontrol edilerek hata (sapma) değeri en aza indirilmeye çalışılırken, test aşamasında ise ağırlık değerleri değiştirilmeksizin giriş değerleri verilerek sonucun tahmin edilmesi istenir [58]. Çalışmada, kayıp iş gününün tahmini için kullanılacak olan ağ içinde girdi bilgileri olarak; kazanın gerçekleştiği ay ve yıl faktörlerinin değerleri alınmıştır.

Bir modelleme işleminin başarısını ifade etmek için kullanılan farklı kriterler geliştirilmiştir. $\mathrm{Bu}$ kriterler geliştirilen modelin temsil ettiği gerçek sistemin giriş değerlerine karşılık gelen deneysel sonuçlar ile modelin giriş değerlerine karşılık ürettiği tahminlerin arasındaki hatanın (farkın) esas almaktadır [59]. Bu çalışmada geliştirilen YSA modellerinin tahmin performansını analiz edebilmek için ve karşılaştırabilmek için belirleme katsayısı $\left(\mathrm{R}^{2}\right)$ ve Karesel Hataların Karekökü (Root Mean Square Error/RMSE) ölçütleri içinde değerlendirilmiştir. 
Tablo 5. YSA eğitim ve test için veri seti

\begin{tabular}{|c|c|c|c|c|c|c|c|}
\hline No & Ay & Yil & $\begin{array}{l}\text { Toplam Kayıp İş } \\
\text { Günü }\end{array}$ & No & Ay & Yll & $\begin{array}{l}\text { Toplam Kayıp İş } \\
\text { Günü }\end{array}$ \\
\hline 1 & 6 & 1 & 10 & 34 & 8 & 4 & 1 \\
\hline 2 & 7 & 1 & 36 & 35 & 9 & 4 & 51 \\
\hline 3 & 8 & 1 & 22 & 36 & 10 & 4 & 75 \\
\hline 4 & 10 & 1 & 105 & 37 & 11 & 4 & 94 \\
\hline 5 & 11 & 1 & 2 & 38 & 3 & 5 & 118 \\
\hline 6 & 1 & 2 & 83 & 39 & 4 & 5 & 21 \\
\hline 7 & 2 & 2 & 20 & 40 & 6 & 5 & 21 \\
\hline 8 & 3 & 2 & 29 & 41 & 7 & 5 & 0 \\
\hline 9 & 4 & 2 & 16 & 42 & 8 & 5 & 110 \\
\hline 10 & 5 & 2 & 13 & 43 & 10 & 5 & 254 \\
\hline 11 & 6 & 2 & 124 & 44 & 11 & 5 & 74 \\
\hline 12 & 7 & 2 & 40 & 45 & 12 & 5 & 101 \\
\hline 13 & 10 & 2 & 126 & 46 & 1 & 6 & 74 \\
\hline 14 & 11 & 2 & 98 & 47 & 2 & 6 & 221 \\
\hline 15 & 12 & 2 & 69 & 48 & 3 & 6 & 227 \\
\hline 16 & 1 & 3 & 20 & 49 & 4 & 6 & 72 \\
\hline 17 & 2 & 3 & 37 & 50 & 5 & 6 & 283 \\
\hline 18 & 3 & 3 & 71 & 51 & 6 & 6 & 43 \\
\hline 19 & 4 & 3 & 5 & 52 & 7 & 6 & 44 \\
\hline 20 & 5 & 3 & 10 & 53 & 8 & 6 & 32 \\
\hline 21 & 6 & 3 & 0 & 54 & 9 & 6 & 201 \\
\hline 22 & 7 & 3 & 10 & 55 & 10 & 6 & 22 \\
\hline 23 & 8 & 3 & 21 & 56 & 11 & 6 & 41 \\
\hline 24 & 9 & 3 & 8 & 57 & 12 & 6 & 126 \\
\hline 25 & 10 & 3 & 23 & 58 & 1 & 7 & 13 \\
\hline 26 & 11 & 3 & 9 & 59 & 2 & 7 & 183 \\
\hline 27 & 12 & 3 & 0 & 60 & 3 & 7 & 7 \\
\hline 28 & 1 & 4 & 76 & 61 & 4 & 7 & 12 \\
\hline 29 & 3 & 4 & 51 & 62 & 5 & 7 & 14 \\
\hline 30 & 4 & 4 & 9 & 63 & 6 & 7 & 32 \\
\hline 31 & 5 & 4 & 11 & 64 & 7 & 7 & 2 \\
\hline 32 & 6 & 4 & 2 & 65 & 9 & 7 & 21 \\
\hline 33 & 7 & 4 & 48 & 66 & 10 & 7 & 4 \\
\hline
\end{tabular}

Tablo 6. YSA analizi değerlendirme kriterleri $\left(\mathrm{R}^{2}\right)$

\begin{tabular}{c|c|c|c|c|c|c|c|c|c}
\hline & \multirow{2}{*}{ No } & \multirow{2}{*}{$\begin{array}{c}\text { Eğitim } \\
\text { Fonk. }\end{array}$} & \multicolumn{3}{|c|}{ Transfer Fonk. } & \multicolumn{2}{c|}{$\begin{array}{c}\text { Nöron } \\
\text { Sayıs }\end{array}$} & Ölçüm \\
& & HD1 & HD2 & Çıkış & $\begin{array}{c}\text { HD } \\
\mathbf{1}\end{array}$ & $\begin{array}{c}\text { HD } \\
\text { Perform. }\end{array}$ & $\begin{array}{c}\text { YSA } \\
\text { Eğitim }\end{array}$ & $\begin{array}{c}\text { YSA } \\
\text { Test }\end{array}$ \\
\cline { 3 - 7 } & & & & & & \\
\hline 1 & Trainlm & Logsig & Logsig & Tansig & 13 & - & & 0.65814 & 0.634158 \\
2 & Trainlm & Logsig & Logsig & Tansig & 15 & - & & 0.81515 & 0.741114 \\
3 & Trainlm & Logsig & Logsig & Tansig & 19 & - & & 0.60997 & 0.598091 \\
4 & Trainlm & Logsig & Logsig & Tansig & 21 & - & & 0.67054 & 0.643539 \\
5 & Trainlm & Logsig & Tansig & Tansig & 27 & - & \multirow{2}{*}{ R $^{2}$} & 0.72638 & 0.681625 \\
6 & Traingda & Tansig & Logsig & Tansig & 13 & 9 & & 0.94117 & 0.730952 \\
7 & Trainscg & Logsig & Logsig & Tansig & 17 & 11 & & 0.92402 & 0.592254 \\
$\mathbf{8}$ & Trainlm & Logsig & Logsig & Tansig & $\mathbf{2 5}$ & $\mathbf{1 1}$ & & $\mathbf{0 . 9 9 8 4 9}$ & $\mathbf{0 . 9 6 6 0 0 7}$ \\
9 & Traingd & Tansig & Tansig & Tansig & 20 & 10 & & 0.24681 & 0.354839 \\
10 & Trainlm & Tansig & Tansig & Logsig & 15 & 3 & & 0.99972 & 0.612034 \\
\hline
\end{tabular}




$$
\begin{aligned}
& R^{2}=1-\left(\frac{\sum\left(V B_{i}-V B_{A N N, i}\right)^{2}}{\Sigma\left(V B_{A N N, i}\right)^{2}}\right) \\
& R M S E=\sqrt{\frac{1}{n} \sum_{t=0}^{n} e_{t}^{2}}
\end{aligned}
$$

Aday çalışanların yıl bazında kaza geçirme risklerinin yüksek olduğu ayların belirlenmesi için kurulan YSA modellerinin performanslarının belirleme katsayısı (Tablo 6) ve RMSE ölçütlerine göre değerlendirilmesi tablo 6 ve 7'de verilmiştir. Model 8'in eğitim ve test sonuçlarının diğerlerine göre daha başarılı olduğu belirlenmiştir.

\begin{tabular}{|c|c|c|c|c|c|c|c|c|}
\hline \multirow{2}{*}{ No } & \multirow{2}{*}{$\begin{array}{l}\text { Eğitim } \\
\text { Fonk. }\end{array}$} & \multicolumn{3}{|c|}{ Transfer Fonk. } & \multicolumn{2}{|c|}{$\begin{array}{l}\text { Nöron } \\
\text { Sayısı }\end{array}$} & \multirow{2}{*}{$\begin{array}{c}\text { Ölçüm } \\
\text { Perform. }\end{array}$} & \multirow{2}{*}{$\begin{array}{l}\text { YSA } \\
\text { Test }\end{array}$} \\
\hline & & HD1 & HD2 & Çıkış & $\begin{array}{c}\text { HD } \\
1\end{array}$ & $\begin{array}{c}\text { HD } \\
2\end{array}$ & & \\
\hline 1 & Trainlm & Logsig & Logsig & Tansig & 13 & - & \multirow{10}{*}{ RMSE } & 0.08256 \\
\hline 2 & Trainlm & Logsig & Logsig & Tansig & 15 & - & & 0.065834 \\
\hline 3 & Trainlm & Logsig & Logsig & Tansig & 19 & - & & 0.152475 \\
\hline 4 & Trainlm & Logsig & Logsig & Tansig & 21 & - & & 0.080586 \\
\hline 5 & Trainlm & Logsig & Tansig & Tansig & 27 & - & & 0.076843 \\
\hline 6 & Traingda & Tansig & Logsig & Tansig & 13 & 9 & & 0.061874 \\
\hline 7 & Trainscg & Logsig & Logsig & Tansig & 17 & 11 & & 0.099145 \\
\hline 8 & Trainlm & Logsig & Logsig & Tansig & 25 & 11 & & 0.040024 \\
\hline 9 & Traingd & Tansig & Tansig & Tansig & 20 & 10 & & 0.354892 \\
\hline 10 & Trainlm & Tansig & Tansig & Logsig & 15 & 3 & & 0.079541 \\
\hline
\end{tabular}

Tablo 7. YSA analizi değerlendirme kriterleri (RMSE)

\section{BULGULAR}

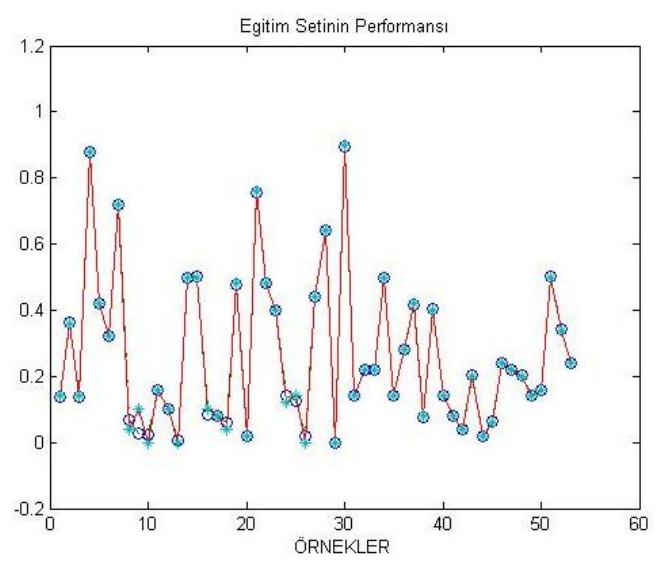

a)Grafiksel gösterim

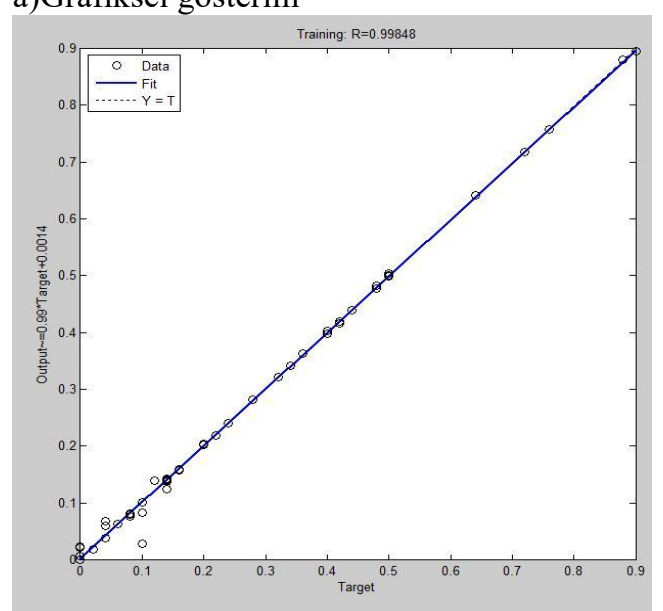

b) Regrasyon analizi

Şekil 5. Eğitim Setinin performans çıktıları

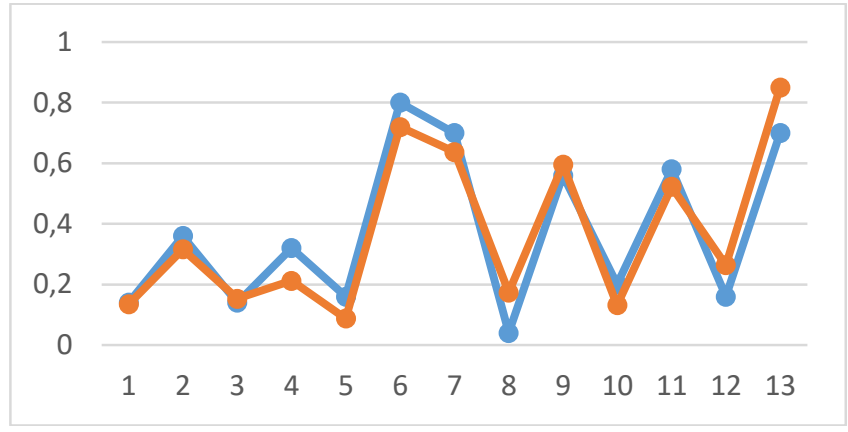

Şekil 6. Set Setinin performans çıktıları

Adaptif Doğrusal Neron ile geliştirilen kurgulanan model giriş katmanı (2 nöron, yıl, ay), çıkış katmanı (kayıp iş günü), iki gizli katman (25/11) oluşmaktadır. Modelin eğitim sonuçları Grafiksel ve regrasyon analizi olarak Şekil 5'de görülmektedir. Modelin test sonuçları Şekil 6'da grafik olarak verilmiştir. YSA modelinde eğitim için \% 99'luk, test için \% 96'lık başarı yakalanmıştır.

YSA modelin test sonuçları incelendiğinde kayıp iş gününü tahmin etmede başarılı olduğu belirlenmiştir. Çalışma da kullanılan kayıp iş günü bir aylık dönemde meydana gelmiş olan iş kazalarında ki kayıp iş günlerini ifade etmektedir.

Dolayısıyla aylık kaza riskini de temsil etmektedir. Bu bağlamda yıllık aylara göre kaza risklerinin belirlenmesi üst yönetimin risk değerlendirme çalışmalarında ciddi bir destek sağlayacaktır. Ayrıca YSA'nın bu alanda uygulanabilirliği test edilmiş olup ileriki çalışmalar için referans niteliği taşıdığı düşünülmektedir. 


\section{DEĞERLENDİRME VE SONUÇ}

İşyerlerinde İş Sağlığı ve Güvenliği birimlerinde yapılan İSG faaliyetleri, iş kazaları ve meslek hastalıklarını önlemekte ya da İSG faaliyetlerinden çalışanları haberdar etmektedir. $\mathrm{Bu}$ tip ISG faaliyetlerdeki organizasyonel eksiklik ya da hatalar, kazaların ve hastalıkların arkasında yatan, kazaya ya da hastalığa maruz kalanın, çevresinin ya da işverenin çektiği acıları tam olarak göstermemektedir. Bununla birlikte kazalıya ya da hastaya maliyeti, işverene maliyeti, topluma maliyeti gibi önemli unsurlarda da çoğu kez yol gösterici olmaktan çok uzaktırlar [60,61].

Birçok işletme İSG performanslarını değerlendirmek için ISG denetlemelerinden geçmiştir. Ancak bu gözden geçirmeler ve denetlemeler kendi başlarına işletmenin performansının yasal gereklerini halen karşıladığı ve gelecekte de karşılamaya devam edeceği konusunda işletmeye güven vermek için yeterli değildir. Bunların etkili olabilmesi için işletme ile entegre olmuş, yapılandırılmış bir Yönetim Sistemi içinde icra edilmeleri gerekir. İşte, İş Sağlığı ve Güvenliğinde karşılaşılabilecek her türlü tehlike ve risklerin sistematik ve verimli biçimde yönetilmesi, İş Sağlığı ve Güvenliği Yönetim Sistemleri aracılığıyla olur. Çalışma ortamlarındaki olası tehlikelerin tespit edildiği ve riskleri minimize etmek için ilgili mevzuata ve standartlara uygun programların oluşturulduğu ve uygulandığı yönetim felsefesi olan İş Sağlığı ve Güvenliği Yönetim Sistemi, İş Sağlığ1 ve Güvenliği risklerine proaktif müdahaleyi kullanan bir yaklaşımdır. Böylece kaynakların gereksiz olarak tekrar kullanımı önlenecektir. İşletme organizasyon yönetimi ile İş Sağlığı ve Güvenliği risk yönetimi birleştirilmiş bütün sistemin bir parçası olmalıdır. Yani, risk yönetimi için yöntemler ve özellikle İş Sağlığ1 ve Güvenliği riski, diğer planlama ve yönetim aktiviteleri ile birleştirilmelidir. Diğer bir anlatımla, yönetimi süreçlerinin uyduğu veya karşılıklı etkileştiği diğer süreçler ile, İş Sağlığı ve İş Güvenliği Yönetim süreci birleştirilir. Böylece kaynakların gereksiz olarak tekrar tekrar kullanımı önlenecektir [20, 62, 63].

Yapılan çalışmada, kurgulanan modele katılan yeni girişlerin kazandığı deneyimlere göre, aday çalışanların yıl bazında kaza geçirme risklerinin tahminiyle, üst yönetime güvenilir bir karar desteği sağlanması hedeflenmiştir.

Sonraki çalışmada, kapsam genişletilerek bir fabrikadaki bulunan meslek gruplarının yıllık kaza geçirme olasılıklarının YSA kullanılarak tahmini yapılabilir. Böyle bir çalışma İSG-YS'de yapılacak planlamalarda ve alınacak tedbirlerin belirlenmesinde önemli bir rol oynayacaktır.

\section{KAYNAKÇA}

[1].BS 8800, Guide to Occupational Health and Sefety Management Systems, British Standards, 1996.

[2].OHS 18000, Occupational Health and Safety Management Systems, Guidelenes for the Implementation of OHSAS 18001, Assesment Series, 2000.

[3].E. N., Dizdar, "Tehlike Değerlendirme Teknikleri”, Yüksek Lisans Tezi, Gazi Üniversitesi, Fen Bilimleri Enstitüsü, Ankara, 2002.
[4].ISO 9001, Quality Management Systems Requirements, ISO, 2000.

[5].ISO 9000, Quality Management Systems Fundamentals and Vocabulary, ISO, 2005.

[6].P., Goosen, Management System in OHS, Analysis and Comparison of OHS Management System Norms. ISAG, Ankara, 2005.

[7].S.S, Kudryavtsev, PV, Yemelin, NK, Yemelina, "The Development of a Risk Management System in the Field of Industrial Safety in the Republic of Kazakhstan", Safety And Health At Work, vol. 9, no: 1, pp. 30-41, 2018.

[8].Y., Sui, R., Ding, HQ, Wang, "An integrated management system for occupational health and safety and environment in an operating nuclear power plant in East China and its management information system", Journal Of Cleaner Production, Vol. 183, pp. 261-271, 2018.

[9].E. N., Dizdar, İş Güvenliği, Murathan Yayınevi, (4. Bask1), Trabzon, 2008.

[10]. L.S., Robson, J.A., Larke, K.L., Cullen, Q., Mahood, "The effectiveness of occupational health and safety management system interventions: A systematic review", Safety Science, Vol. 25, no: 3, pp. 329-353, 2007.

[11]. E., Hollnagel, "Safety-I and safety-II: The Past And Future Of Safety Management", Cognition Technology and Work, Vol. 17, no: 3, pp. 461-464, 2014.

[12]. OHSAS 18002, Occupational Health and Safety Management Systems - Guidelines for the implementation of OHSAS 18001, 2000.

[13]. ILO, Guidelines on Occupational Safety and Health Management Systems. Geneva: International Labour Office, 2001.

[14]. E. N., Dizdar, Kaza Sebeplendirme Yaklaşımları, Mesleki Sağlık ve Güvenlik, 2001.

[15]. OHS-MS, International Labour Organization, Guidelines on Occupational Health and Safety Management Systems, 2001.

[16]. F., Goerlandt, N., Khakzad, G., Reniers, "Special Issue: Risk Analysis Validation and Trust in Risk management", Safety Science, vol. 99, pp.123-131, 2017.

[17]. S.P., Levine, DT., Dyjack., "Critical features of an auditable Management System for an ISO 9000-compatible occupational health and Safety standard", American Industrial Hygiene Association Journal, Vol. 58, no: 4, pp. 291-298, 1997.

[18]. E. N., Dizdar, Üretim Sistemlerinde Olası İş Kazaları İçin Bir Erken Uyarı Modeli, Doktora Tezi, Gazi Üniversitesi Fen Bilimleri Enstitüsü Endüstri Mühendisliği, Ankara, 1998.

[19]. M.P., Cottam, Certification of occupational health and Safety Management systems, Foresight And Precaution, Conference on Foresight and Precaution, 455461, 2000.

[20]. E. N. Dizdar, Risk Değerlendirme ve Yönetim Sistemi, İş Sağlığı ve Güvenliği Yönetim Sistemleri, AÜAÖF Yayınları, 2014.

[21]. K. W. J. Frick, Reviewing Occupational Health and Safety Management, Multiple Roots. Amsterdam: Elsevier, 2000. 
[22]. E. N. Dizdar, Ünal, Ç., Kurumsal Yapının Değerlendirilmesi, İSGGM Çalıştayı, Antalya, 2010.

[23]. A.H., Jespersen, P., Hasle, "Developing a concept for external audits of psychosocial risks in certified occupational health and Safety Management Systems", Safety Science, Vol. 99, pp. 227-234, 2017.

[24]. ISO 19011, 2005. Guidelines For Quality And Environmental Management Systems Auditing, ISO, 2002.

[25]. F.E., Ciarapica, G.. Giacchetta, "Classification and Prediction of Occupational Injury Risk Using Soft Computing Techniques: An Italian Study", Safety Science, Vol. 47, pp. 36-49, 2009.

[26]. J., Khorsandi, T., Aven, "Incorporating assumption deviation risk in quantitative risk assessments: A semi-quantitative approach", Reliability Engineering \& System Safety, Vol. 163, pp. 22-32, 2017.

[27]. D.E., Nordgård, "A Framework For Risk-Informed Decision Support in Electricity Distribution Companies Utilizing Input From Quantitative Risk Assessment", International Journal of Electrical Power \& Energy Systems, Vol. 43, no: 1, pp. 255-264, 2012.

[28]. K., Kazaras, K., Kirytopoulos, "Challenges for current quantitative risk assessment (QRA) models to describe explicitly the road tunnel safety level", Journal of Risk Research, Vol. 17, no:8, pp.953-963, 2014.

[29]. Z., Zeng, E., Zio, "A classification-based framework for trustworthiness assessment of quantitative risk analysis", Safety Science, Vol. 99, pp. 215-226, 2017.

[30]. G.E., Apostolakis, "How Useful Is Quantitative Risk Assessment?”, Risk Analysis Journal, Vol. 24, No:3, pp. 515-520, 2004.

[31]. Z.Q, Liu, H. W., Huang, Y. D., Xue, "The Application of Quantitative Risk Assessment in Talus Slope Risk Analysis", Georisk: A ssessment and Management of Risk for Engineered Systems and Geohazards, Vol. 3, no: 3, pp.155-168, 2009.

[32]. F., Goerlandt, N., Khakzad, G., Reniers, "Validity and validation of safety-related quantitative risk analysis: A review", Safety Science, Vol. 99, pp.127-138, 2017.

[33]. H.J., Pasman, WR., Rogers, MS., Mannan, "Risk assessment: What is it worth? Shall we just do away with it, or can it do a better job?", Safety Science, 2017ol. 99, pp.140, 2017.

[34]. A., Rae, R., Alexander, J., "McDermid, Fixing the cracks in the crystal ball: A maturity model for quantitative risk assessment",Reliability Engineering \& System Safety, Vol. 125, pp.67-76, 2014

[35]. T., Aven, "Supplementing Quantitative Risk Assessments With A Stage Addressing The Risk Understanding Of The Decision Maker", Reliability Engineering \& System Safety, Vol. 152, pp. 51, 2016.

[36]. S., Choe, F., Leite, "Assessing Safety Risk among Different Construction Trades: Quantitative Approach", Journal of Construction Engineering and Management, Vol. 143, pp. 5-12, 2017.

[37]. F.W, Guldenmund, "Misunderstanding Safety Culture and Its Relationship to Safety Management", Risk Analysis, Vol. 30, no. 10. First Publ, 2010.
[38]. Y., Sui, R., Ding, HQ, Wang, "An integrated management system for occupational health and safety and environment in an operating nuclear power plant in East China and its management information system", Journal Of Cleaner Production, Vol. 183, pp. 261-271, 2018.

[39]. K.F., Walter, Workers Participation and the Management of Occupational Health and Safety; Reinforcing or Conflicting Strategies, Pergamon, 2000.

[40]. Ö. Özkılıç, "İş Sağlığı, Güvenliği ve Çevresel Etki Risk Değerlendirmesi”, TİSK Yayınları, Yayın No:540, 2007.

[41]. V., Seber,. "İşçi Sağlığı Ve Güvenliğinde Risk Analizleri Nasıl Yapılır”, TMMOB Elektrik Mühendisliği, Vol. 445, pp.30-34, 2013.

[42]. D., Ramos, A., Costa, P., Afonso, Integration of Risk Management in Occupational Health and Safety Systems, Proceedings of The 2nd International Conference On Project Evaluation, ICOPEV International Conference on Project Economic Evaluation, 237-246, (2014).

[43]. L., Mussone, A., Ferrar1, M., Oneta, "An Analysis Of Urban Collisions Using An Artificial Intelligence Model", Accident Analysis Prevent, Vol. 31 , no: 6, pp. 705-718, 1999.

[44]. S., Sohn, S., Lee, "Data Fusion, Ensemble And Clustering to Improve The Classification Accuracy For The Severity Of Road Traffic Accident İn Korea", Safety Science, Vol. 41, no: 1, pp.1-14, 2003.

[45]. M., Abdel-Aty, A. Pande, "Identifying Crash Propensity Using Traffic Speed Conditions”, J. Safety Res. Vol. 36, no: 1, pp. 97-108, 2005.

[46]. L.Y., Chang, "Analysis Of Freeway Accident Frequencies: Negative Binomial Regression Versus Artificial Neural Network", Safety Science, Vol. 43, pp.541-557, 2005.

[47]. F.H., Bayata, F., Hattatoğlu, "Yapay Sinir Ağları ve Çok Değişkenli İstatislik Yönetemlerle Trafik Kaza Modellenmesi”, Fen Bilimleri Enstitüsü Dergisi, Vol. 3, no: 2, pp. 207-219, 2010.

[48]. A.P., Akgüngör, E., Doğan, "Estimating Road Accidents of Turkey Based on Regression Analysis and Artificial Neural Network Approach", Advances in Transportation Studies an international Journal, Section A, Vol. 16, pp. 11-22, 2008.

[49]. A.P., Akgüngör, E., Doğan, "Farklı Yöntemler Kullanılarak Geliştirilen Trafik Kaza Tahmin Modelleri ve Analiz", Int. J. Eng. Research\&Development, Vol. 2, no. 1, pp.:16-20, 2010.

[50]. V.D., Tsoukalas, N.G., Fragıadak1s, "Prediction of Occupational Risk in The Ship building Industry Using Multivariable Linear Regressionand Genetic Algorithm Analysis", Safety Science, Vol. 83, pp.12-22, 2016.

[51]. V.D., Tsoukalas, N.G., Fragiadak1s, "An Adaptive Neuro-Fuzzy İnference System (Anfis) Model For Assessing Occupational Risk in Ship Building İndustry”, Safety Science, Vol. 63, pp.226-235, 2014.

[52]. S.B., Murugan, ML., Sundar, "Investigate safety and quality performance at construction site using artificial 
neural network", Journal of Intellingent \& Fuzzy Systems, Vol. 33, no.4, pp. 2211-2222, 2017.

[53]. D.L., Mario, "A comparison between prediction power of artificial neural networks and multivariate analysis in road safety management", Transport, Vol. 32, no. 4, pp.379,385, 2017.

[54]. A.M, Abubakar, H., Karadal, SW., Bayighomog, E., Merdan,. "Workplace Injuries, Safety Climate and Behaviors: Application of Artificial Neural Network", Int. Journal Safety and Ergonomics, Jose, Vol.19, pp. 1-32, 2018.

[55]. E. Öztemel, Yapay Sinir Ağları, Papatya Bilim Yayınevi, 7. Sayı, İstanbul, 2006.

[56]. Ç., Elmas, Yapay Zeka Uygulamaları, Seçkin Yayınevi, Ankara, 2007.

[57]. D., Karayel, "Predictionand Control of Surface Roughness in CNC Lathe Using Artifical Neural Network, Journal of Materials Processing Technology" , Vol. 209, pp.3125-3137, 2009.

[58]. S., Stauba, E., Karamand, S., Kayaa, H., Karapönara, E., Güven, "Artificial Neural Network and Agility”, Procedia - Social and Behavioral Sciences, Vol. 95, pp. 1477-1485, 2015.
Ş., Karabulut, "Vermiküller Grafitli Dökme Demirin Frezelemedeki İşlenebilirliğinin Deneysel Olarak Araştırılması ve Yapay Sinir Ağlarıyla Modellenmesi”, Doktora Tezi, Gazi Üniversitesi Makine Eğitimi Bölümü, 195 s, Ankara, 2012.

[59]. A.M., Makin, C., Wilder, "A new conceptual framework to improve the application of occupational health and Safety Management Systems", Safety Science, Vol. 46, no. 6, pp. 935-948, 2008.

[60]. YL, Li., FW., Guldenmund, "Safety Management System: A broad overview of the literatüre", Safety Science, Vol. 103, pp. 94-123, 2018.

[61]. D.G., Ramos, C., Costa, "Occupational Health and Safety Management System: A case study in a waste company", Occupational Safety And Hygiene IV, pp. $597-$ 601, 2016.

[62]. A., Pereira, S.,Ahn, S., Han, S., Abourizk, "Identification and Association of High-Priority Safety Management System Factors and Accident Precursors for Proactive Safety Assessment and Control", Journal Of Management In Engineering, vol. 34, no. 1, pp.104-112. 2018. 